\title{
Contribuição de solutos orgânicos e inorgânicos no ajustamento osmótico de pinhão-manso submetido à salinidade
}

\author{
Evandro Nascimento da Silva( ${ }^{(1)}$, Joaquim Albenísio Gomes Silveira(1), Cícera Raquel Fernandes Rodrigues ${ }^{(1)}$, \\ Cristina Silva de Lima ${ }^{(1)}$ e Ricardo Almeida Viégas ${ }^{(2)}$
}

\begin{abstract}
(1)Universidade Federal do Ceará, Departamento de Bioquímica e Biologia Molecular, Caixa Postal 6020, CEP 60451-970 Fortaleza, CE. E-mail: evandrons@oi.com.br, silveira@ufc.br, quelfer09@hotmail.com, crysz.lima@gmail.com (2)Universidade Federal de Campina Grande, Departamento de Engenharia Florestal, Caixa Postal 64, CEP 58700-970 Patos, PB. E-mail: raviegas@uol.com.br
\end{abstract}

\begin{abstract}
Resumo - O objetivo deste trabalho foi avaliar a acumulação de solutos orgânicos e inorgânicos e suas contribuições para o ajustamento osmótico de folhas de pinhão-manso (Jatropha curcas L.) submetido à salinidade. $\mathrm{O}$ experimento foi conduzido em delineamento experimental inteiramente casualizado, com cinco tratamentos $\left(0,25,50,75\right.$ e $100 \mathrm{mmol} \mathrm{L}^{-1}$ de $\left.\mathrm{NaCl}\right)$ e quatro repetições. As plantas foram cultivadas hidroponicamente em casa de vegetação, em condições controladas de fotoperíodo (12 horas), temperatura (média de $28^{\circ} \mathrm{C}$ ) e umidade relativa do ar (média de $65 \%$ ), com radiação fotossinteticamente ativa máxima média de $700 \mu \mathrm{mol} \mathrm{m}^{-1} \mathrm{~s}^{-1}$. O potencial osmótico das folhas decresceu progressivamente e variou de $-0,84 \mathrm{a}-2,05 \mathrm{MPa}$, enquanto o conteúdo relativo de água aumentou nos tratamentos com 75 e $100 \mathrm{mmol} \mathrm{L}^{-1}$. Os íons $\mathrm{Na}^{+}$e $\mathrm{Cl}^{-}$ foram os mais importantes, em termos quantitativos, e contribuíram com cerca de 52 e $20 \%$, respectivamente, para o ajustamento osmótico das folhas de plantas tratadas com $\mathrm{NaCl}$. A contribuição do $\mathrm{K}^{+}$decresceu de modo acentuado e foi de 17 e $5 \%$ nos tratamentos com 25 e $100 \mathrm{mmol} \mathrm{L}^{-1}$ de $\mathrm{NaCl}$. A contribuição média dos solutos orgânicos, açúcares, aminoácidos, glicina betaína e prolina, foi de 5,5, 6, 4 e $0,03 \%$, respectivamente. As folhas de pinhão-manso ajustam-se osmoticamente em presença de salinidade, e mantêm bom nível de hidratação, principalmente por meio da acumulação de $\mathrm{Na}^{+} \mathrm{e} \mathrm{Cl}^{-}$. A glicina betaína tem papel quantitativo mais importante do que a prolina no ajustamento osmótico, tanto em presença quanto em ausência de salinidade.
\end{abstract}

Termos para indexação: Jatropha curcas, estresse salino, potencial osmótico, solutos orgânicos.

\section{Contribution of organic and inorganic solutes to osmotic adjustment of physic nut under salinity}

\begin{abstract}
The objectives of this work were to evaluate the organic and inorganic solutes accumulation and measure their contribution to the osmotic adjustment of physic nut (Jatropha curcas L.) leaves under salinity. The experiment was carried out using a completely randomized design with five treatments $(0,25,50,75$, and $100 \mathrm{mmol} \mathrm{L}^{-1}$ of $\mathrm{NaCl}$ ) and four replications. Plants were hydroponically grown under greenhouse controlled conditions of photoperiod ( 12 hours), temperature (average of $28^{\circ} \mathrm{C}$ ), relative humidity (average of $65 \%$ ), and with maximum photosynthetically active radiation average of $700 \mu \mathrm{mol} \mathrm{m}^{-1} \mathrm{~s}^{-1}$. The leaf osmotic potential decreased progressively, changing from -0.84 to $-2.05 \mathrm{MPa}$, while the relative water content increased in the 75 and $100 \mathrm{mmol} \mathrm{L}^{-1}$ treatments. The relative contribution of $\mathrm{Na}^{+}$and $\mathrm{Cl}^{-}$ions were the most important quantitatively for the leaf osmotic adjustment of salt-treated plants, 52 and $20 \%$, respectively. The relative contribution of $\mathrm{K}^{+}$decreased significantly with added salt, changing from 17 to $5 \%$ as the $\mathrm{NaCl}$ level increased from 25 to $100 \mathrm{mmol} \mathrm{L}^{-1}$. The average contribution of sugars, amino acids, glycinebetaine, and proline was approximately 5.5, 6, 4, and $0.03 \%$, respectively. The physic nut leaves exhibited an effective osmotic adjustment under salinity, maintaining their hydration status, mainly via $\mathrm{Na}^{+}$and $\mathrm{Cl}^{-}$accumulation. Glycinebetaine was more important to osmotic adjustment than proline in both salt-treated and untreated plants.
\end{abstract}

Index terms: Jatropha curcas, salt stress, osmotic potential, organic solutes.

\section{Introdução}

O pinhão-manso (Jatropha curcas L.) é uma espécie oleaginosa viável para a obtenção do biocombustível, pois produz, no mínimo, $2 \mathrm{Mg}$ de óleo por hectare
(Saturnino et al., 2005). Esses autores relatam que os graves problemas a ser enfrentados pelos produtores, no cultivo da espécie em região semiárida, são a salinidade e a salinização dos solos. No caso de cultivo de sequeiro, será provável a expansão para

Pesq. agropec. bras., Brasília, v.44, n.5, p.437-445, maio 2009 
solos naturalmente salinizados, que são amplamente distribuídos na região Nordeste do Brasil. Na agricultura irrigada, as condições de elevada evapotranspiração, baixa qualidade das águas e baixa pluviosidade em muito deverão contribuir para a salinização secundária. Tal cenário, especialmente no médio e longo prazos, deverá não somente limitar a produtividade de pinhãomanso, como também inviabilizar outras culturas.

Para suportar o estresse salino, as plantas têm desenvolvido mecanismos complexos, que contribuem para a adaptação aos estresses osmótico e iônico, provocados pela alta salinidade (Meloni et al., 2004). Esses mecanismos incluem o ajustamento osmótico, que é usualmente acompanhado pela absorção de íons inorgânicos, bem como pela acumulação de solutos orgânicos compatíveis (osmoprotetores) (Strange, 2004). Íons inorgânicos são sequestrados no vacúolo, enquanto os solutos orgânicossão compartimentalizados no citoplasma, para balancear o baixo potencial osmótico nos vacúolos (Taiz \& Zeigher, 2004).

$\mathrm{O}$ acúmulo de compostos inorgânicos $\left(\mathrm{Na}^{+}, \mathrm{K}^{+} \mathrm{e} \mathrm{Cl}\right)$ é bem evidenciado em condições de estresse salino; embora esses elementos tenham papel importante no crescimento de plantas superiores nessas condições, suas contribuições relativas variam entre as espécies, entre as cultivares de uma mesma espécie, entre órgãos e tecidos de uma mesma planta e até entre diferentes compartimentos de uma célula (Asharaf \& Harris, 2004). Recentemente, Silveira et al. (2009) observaram que os íons $\mathrm{Na}^{+}$e $\mathrm{Cl}^{-}$são os solutos mais importantes no ajustamento osmótico de folhas e raízes de Atriplex nummularia, e que $\mathrm{K}^{+}$tem sua contribuição diminuída intensamente pela salinidade.

Entre os compostos orgânicos, os nitrogenados - aminoácidos, inclusive a prolina e compostos quaternários de amônio, entre eles a glicina betaína e os poli-hidroxílicos (carboidratos e poliálcoois) são os solutos mais comumente acumulados em plantas em condições de estresse (Asharaf \& Harris, 2004). O acúmulo de aminoácidos e de carboidratos solúveis tem sido estudado intensamente em plantas em condições de estresse salino (Azevedo Neto et al., 2004), pois são os solutos orgânicos de maior contribuição para o potencial osmótico.

O objetivo deste trabalho foi avaliar o acúmulo de solutos orgânicos e inorgânicos e suas respectivas contribuições para o ajustamento osmótico em folhas de pinhão-manso, em diferentes concentrações de $\mathrm{NaCl}$.

\section{Material e Métodos}

O experimento foi conduzido em casa de vegetação, no Departamento de Bioquímica e Biologia Molecular, da Universidade Federal do Ceará, em Fortaleza, CE $\left(3^{\circ} 44^{\prime} \mathrm{S}\right.$ e $\left.38^{\circ} 33^{\prime} \mathrm{W}\right)$. O clima local é do tipo AW, de acordo com a classificação de Köppen. O período experimental foi de março a abril de 2008. As condições ambientais no interior da casa de vegetação foram: fotoperíodo de 12 horas, temperatura média mínima de $24^{\circ} \mathrm{C}$, temperatura máxima de $36^{\circ} \mathrm{C}$, temperatura média diária de $28^{\circ} \mathrm{C}$, umidade relativa do ar média de $65 \%$ e radiação fotossinteticamente ativa máxima média de aproximadamente $700 \mu \mathrm{mol} \mathrm{m} \mathrm{m}^{-2} \mathrm{~s}^{-1}$.

Foram utilizadas sementes de pinhão-manso (Jatropha curcas L.) fornecidas pelo Instituto Fazenda Tamanduá, de São João do Bonfim, PB. Sementes previamente selecionadas por tamanho e peso foram germinadas em areia, e as plântulas foram mantidas por oito dias, até posterior transferência para vasos de $2 \mathrm{~L}$, com solução de Hoagland \& Arnon (1950) diluída 1/4 na primeira semana e $1 / 2$ na segunda semana, com $\mathrm{pH} 6$, ajustado a cada dois dias com $\mathrm{NaOH} 0,1 \mathrm{~mol} \mathrm{~L}^{-1}$ ou $\mathrm{HCl} 0,1 \mathrm{~mol} \mathrm{~L}^{-1}$. Na terceira semana, iniciaram-se os tratamentos com $\mathrm{NaCl}$ por meio da adição diária de $25 \mathrm{mmol} \mathrm{L}^{-1}$ até atingir as concentrações de 25, 50, 75 e $100 \mathrm{mmol} \mathrm{L}^{-1}$, no quarto dia. Em seguida, as plantas permaneceram por mais 11 dias em exposição aos tratamentos de $\mathrm{NaCl}$. As plantas cultivadas na ausência de $\mathrm{NaCl}$ foram consideradas como controle.

$\mathrm{O}$ delineamento experimental foi inteiramente casualizado, com cinco tratamentos $-0,25,50,75$ e $100 \mathrm{mmol} \mathrm{L}^{-1}$ de $\mathrm{NaCl}$ - e quatro repetições. A parcela experimental foi representada por um vaso com uma planta, e o total foi 20 parcelas experimentais. Os resultados foram submetidos à análise de variância, e as médias foram comparadas pelo teste de Tukey $(\mathrm{p}<0,05)$.

Após a coleta, foi feita pesagem da matéria fresca das folhas que foram, posteriormente, transferidas para secagem em estufa com circulação de ar a $75^{\circ} \mathrm{C}$, por 48 horas. Após esse período, foi determinada a massa de matéria seca. Para a determinação do conteúdo relativo de água (CRA), foram coletados 30 discos foliares de $1 \mathrm{~cm}$, dos quais foi determinada a massa de matéria fresca (MF1). Os discos foliares foram transferidos para placas de Petri com água destilada e deixados sobre uma bancada por 6 horas. A seguir, os discos foram removidos e colocados entre folhas de papel 
de filtro, pressionados para eliminação do excesso de água e, em seguida, foram pesados novamente (MF2). Logo após, os discos foram colocados em sacos de papel e postos em estufa a $75^{\circ} \mathrm{C}$ por 48 horas. Foi, então, determinada a massa de matéria seca do material (MS). O conteúdo relativo de água foi calculado pela equação: CRA $=100[(\mathrm{MF} 1$ - MS)/(MF2 - MS) $]$, e a suculência foliar $(\mathrm{SF})$ pela equação: $\mathrm{SF}=\mathrm{MF} 1 / \mathrm{A}$, em que A representa a área de 30 discos.

Para a determinação da osmolalidade total do tecido foliar, foram coletadas folhas do terço médio da parte aérea da planta, que foram maceradas em almofariz com pistilo. A seiva obtida do tecido foi filtrada e centrifugada a $10.000 \mathrm{~g}$ por $10 \mathrm{~min}$ a $4^{\circ} \mathrm{C}$. Uma alíquota de $10 \mu \mathrm{L}$ do sobrenadante foi utilizada para a determinação da osmolalidade do tecido, com um osmômetro de pressão de vapor Vapro 5520 (Wescor, Inc., Logan, UT, USA). Os valores obtidos em milimoles por quilograma foram convertidos em potencial osmótico, por meio da equação de Van't Hoff, com a fórmula:

$1 \mathrm{mmol} \mathrm{kg} \mathrm{kg}^{-1}=-\mathrm{c}\left(\operatorname{mosmol~\mathrm {kg}^{-1}}\right) \times 2,58 \times 10^{-3}$. $\mathrm{O}$ ajustamento osmótico foi estimado pela diferença no potencial osmótico entre plantas com e sem estresse.

Os solutos inorgânicos e os orgânicos foram extraídos de tecidos foliares liofilizados, previamente congelados em $\mathrm{N}_{2}$ líquido. Amostras pulverizadas foram transferidas para tubos hermeticamente fechados, na presença de água deionizada, e colocados em banho-maria a $100^{\circ} \mathrm{C}$ por 1 hora. Os extratos foram filtrados e armazenados em freezer a $-20^{\circ} \mathrm{C}$. Os conteúdos de sódio e potássio foram determinados por fotometria de chama, e o conteúdo de cloreto, pela titulação com $\mathrm{AgNO}_{3}$. Os teores de nitrato foram determinados segundo método de Cataldo et al. (1975). A determinação dos teores de açúcares solúveis totais foi realizada pelo método de Dubois et al. (1956). Os teores de aminoácidos livres totais e glicina betaína foram determinados segundo Silveira et al. (2009), as concentrações de prolina, segundo método de Silveira et al. (2003).

Todas as concentrações de solutos foram expressas em milimoles por quilograma de água no tecido, após correção da umidade (Silveira et al., 2009). A contribuição de cada soluto para o potencial osmótico foi estimada como percentagem da osmolalidade, por meio da seguinte relação: conteúdo do soluto ( $\mathrm{mmol}$ do soluto $\mathrm{kg}^{-1}$ de água no tecido)/osmolalidade (mmol kg-1 do solvente) x 100 .

\section{Resultados e Discussão}

O estresse salino acarretou decréscimo significativo no crescimento foliar, em plantas jovens de pinhãomanso, após 15 dias de tratamento. Mesmo na concentração mais baixa de $\mathrm{NaCl}\left(25 \mathrm{mmol} \mathrm{L}^{-1}\right)$, a massa de matéria seca sofreu uma redução de aproximadamente 25\%, em comparação com o controle (Figura $1 \mathrm{~A}$ ). Entre os tratamentos com 50, 75 e $100 \mathrm{mmol} \mathrm{L}^{-1}$ de $\mathrm{NaCl}$, não houve diferenças significativas. Essa redução foi acompanhada por intensos sintomas visuais de toxicidade causados pelo estresse salino, caracterizados por clorose seguida de necrose, inicialmente em áreas localizadas das folhas com progressiva expansão, em consequência da dose de $\mathrm{NaCl}$ e do tempo de exposição.

Apesar dos efeitos tóxicos da salinidade sobre as folhas de pinhão-manso, os indicadores de estado hídrico, conteúdo relativo de água (CRA) e suculência foliar não diminuíram na presença do sal. Ao contrário, nos tratamentos com 75 e $100 \mathrm{mmol} \mathrm{L}^{-1}$ de $\mathrm{NaCl}$, houve aumento significativo dessas variáveis, em relação ao controle (Figura 1 B e C). Portanto, o estresse salino não afetou negativamente $\mathrm{o}$ grau de hidratação das folhas, e o excesso de íons acumulados contribuiu para a retenção de água no tecido.

$\mathrm{O}$ aumento nos valores da suculência foliar e no conteúdo relativo de água induzido pelo $\mathrm{NaCl}$ são indicativos de ter ocorrido um efetivo ajustamento osmótico em plantas com estresse, conforme observado por Martínez et al. (2004). Os efeitos da salinidade sobre o potencial osmótico estão apresentados na Figura1 D, em que se observa que esse parâmetro foi sistematicamente reduzido em plantas tratadas com $\mathrm{NaCl}$. A variação foi de $-0,84\left(0 \mathrm{mmol} \mathrm{L}^{-1}\right)$ a $-2,05 \mathrm{MPa}$ em $100 \mathrm{mmol} \mathrm{L}^{-1}$ de $\mathrm{NaCl}$. Vários autores relatam que a redução do potencial osmótico foliar, em plantas lenhosas submetidas à salinidade, tem como principal causa a maior absorção dos íons $\mathrm{Na}^{+} \mathrm{e} \mathrm{Cl}-$ (Ottow et al., 2005; Silveira et al., 2009).

Os conteúdos de $\mathrm{Na}^{+}$e $\mathrm{Cl}^{-}$foram significativamente maiores em folhas expostas ao sal em comparação ao controle. Os aumentos ocorreram a partir da concentração $25 \mathrm{mmol} \mathrm{L}^{-1} \mathrm{e}$ apresentaram tendência de estabilização a partir de $50 \mathrm{mmol} \mathrm{L}^{-1}$ (Figura $2 \mathrm{~A}$ e B). O conteúdo de $\mathrm{Na}^{+}$na concentração mais elevada de sal atingiu aproximadamente $373 \mathrm{mmol} \mathrm{L}^{-1}$ (expressa na base deágua no tecido), cerca de quatro vezes a concentração de $\mathrm{Na}^{+}$ na solução nutritiva, enquanto a soma das concentrações 
de $\mathrm{Na}^{+}$e $\mathrm{Cl}^{-}$nas folhas, nesse mesmo tratamento, alcançou $520 \mathrm{mmol} \mathrm{L}^{-1}$, valor aproximadamente cinco vezes maior do que a concentração externa na solução. Isso indica que essa espécie não possui mecanismos eficientes de redistribuição e exclusão de $\mathrm{Na}^{+}$e $\mathrm{Cl}^{-}$para atuar na redução do excesso de íons salinos, acumulados na parte aérea de plantas sob salinidade (García-Sánches et al., 2002).
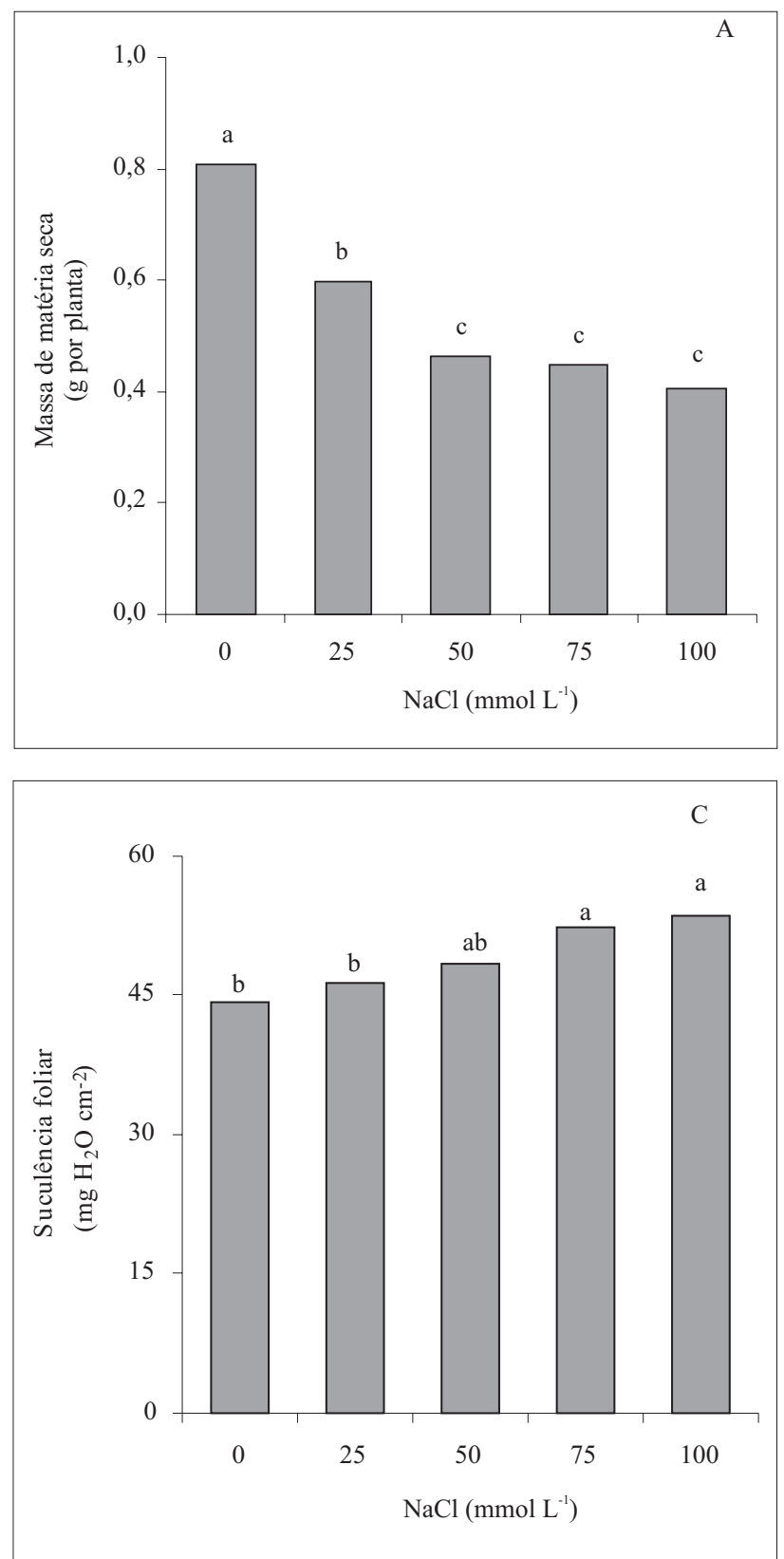

Os íons $\mathrm{Na}^{+} \mathrm{e} \mathrm{Cl}^{-}$contribuíram com aproximadamente 17 e $4 \%$, respectivamente, para o ajustamento osmótico das plantas de pinhão-manso não tratadas com $\mathrm{NaCl}$, enquanto as tratadas apresentaram contribuições médias de 52 e $20 \%$, respectivamente (Tabela 1). Esses dados mostram que os próprios íons salinos são, quantitativamente, os solutos mais importantes para o ajustamento osmótico de folhas de pinhão-manso submetido à salinidade. Esse tipo
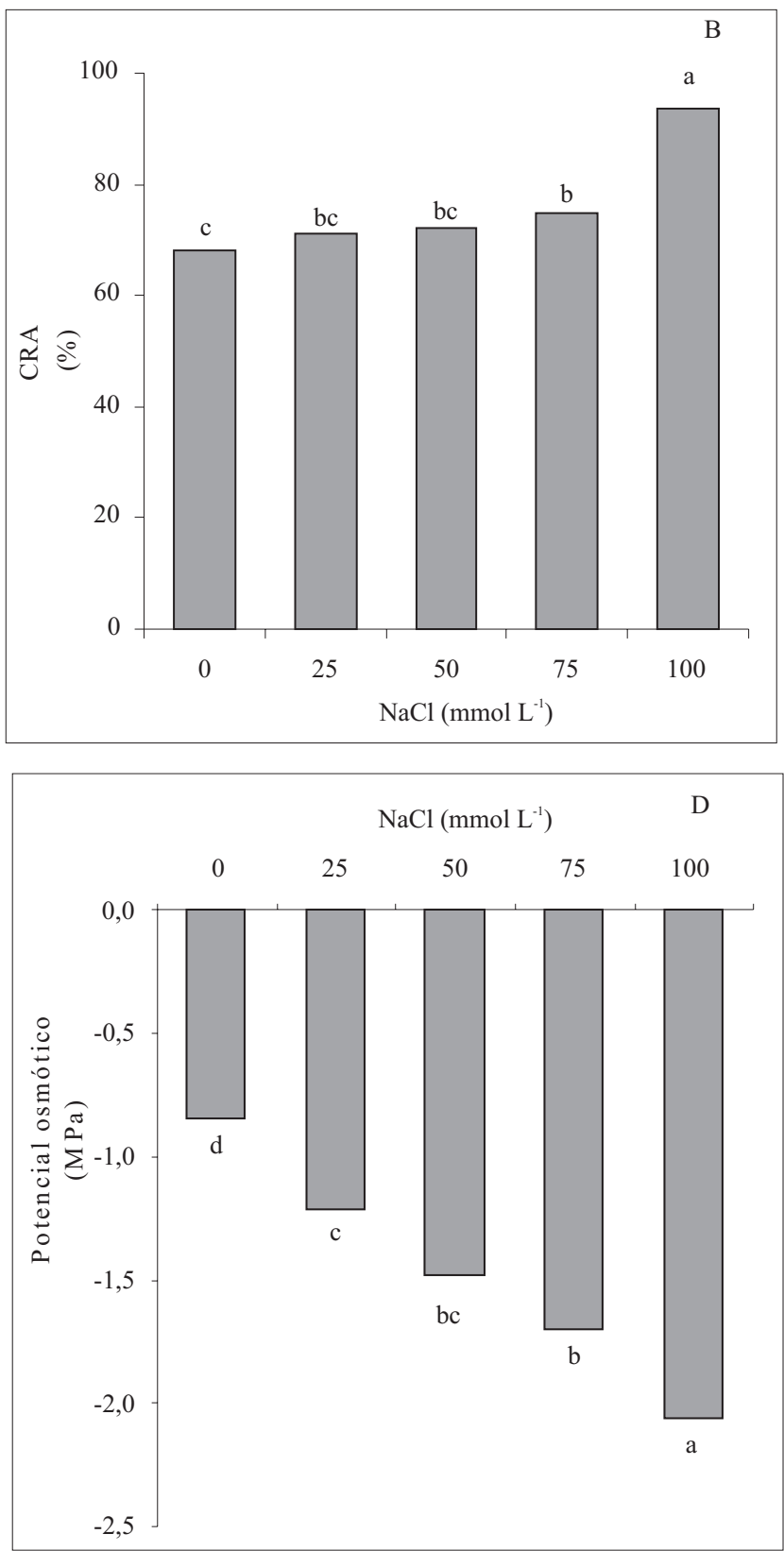

Figura 1. Massa de matéria seca (A), conteúdo relativo de água (B), suculência foliar (C) e potencial osmótico (D) em folhas de pinhão-manso, expostas a diferentes concentrações de $\mathrm{NaCl}$ durante 15 dias. Tratamentos com letras iguais não diferem entre si a $5 \%$ de probabilidade, pelo teste de Tukey 
de resposta ocorre frequentemente em glicófitas (Ottow et al., 2005) e em halófitas submetidas ao estresse salino (Silveira et al., 2009).

Os conteúdos de $\mathrm{K}^{+}$e $\mathrm{NO}_{3}^{-}$nas folhas foram significativamente menores em plantas expostas ao sal em comparação às do controle (Figura $2 \mathrm{C}$ e D). Essas reduções foram significativas a partir da dose de $25 \mathrm{mmol} \mathrm{L}^{-1} \mathrm{e}$ apresentaram tendência à estabilização
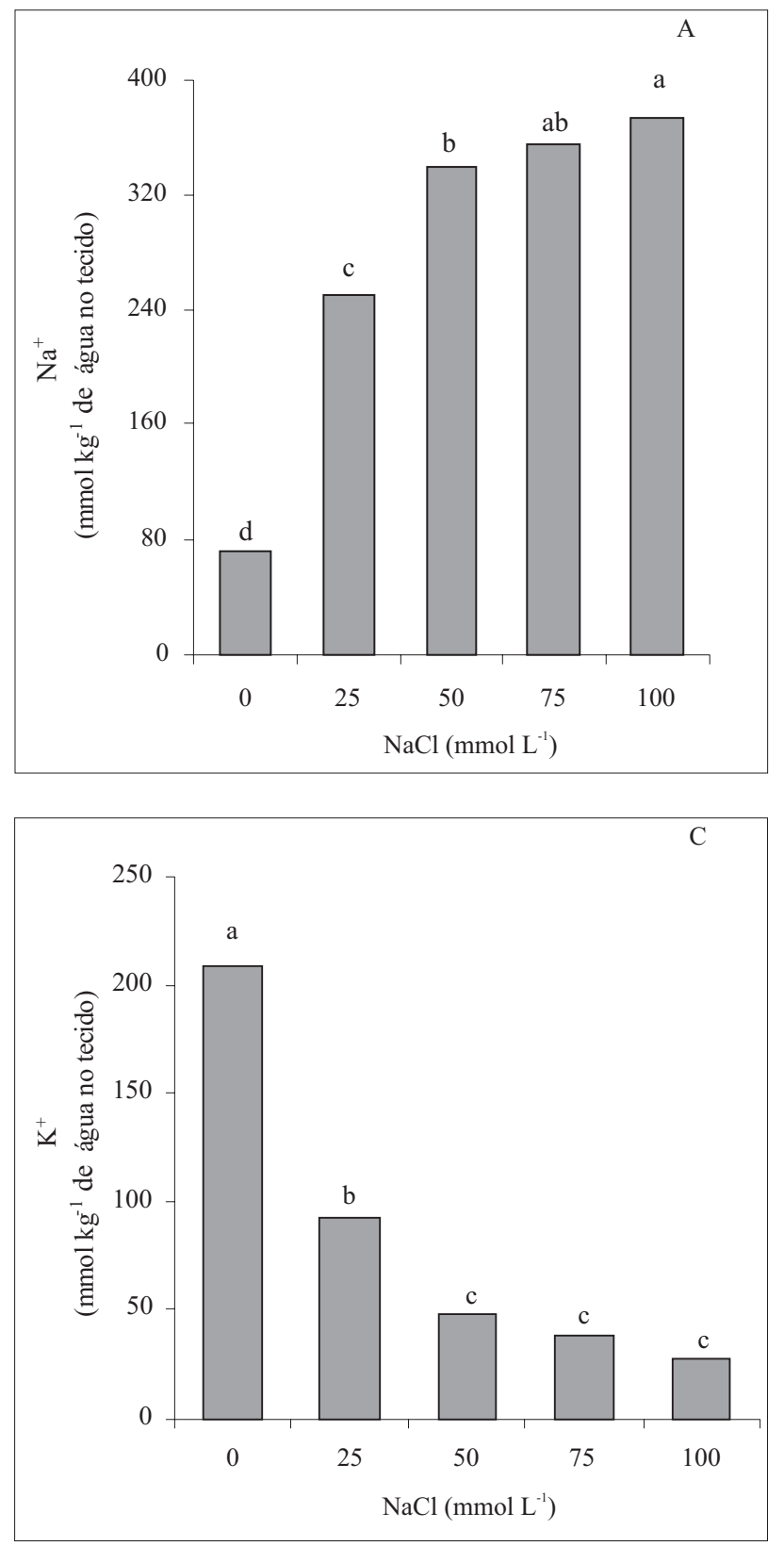

a partir da dose de $50 \mathrm{mmol} \mathrm{L}^{-1}$. Na concentração mais elevada de sal, as reduções de $\mathrm{K}^{+}$e $\mathrm{NO}_{3}^{-}$foram de 89 e $37 \%$, respectivamente. Diminuição na concentração de $\mathrm{K}^{+}$nas folhas com o aumento da salinidade também foi encontrada em milho por Azevedo Neto et al. (2004), enquanto Meloni et al. (2004) observaram diminuições nos teores de nitrato em plantas de algaroba sob estresse salino. Isso demonstra que reduções nos conteúdos de
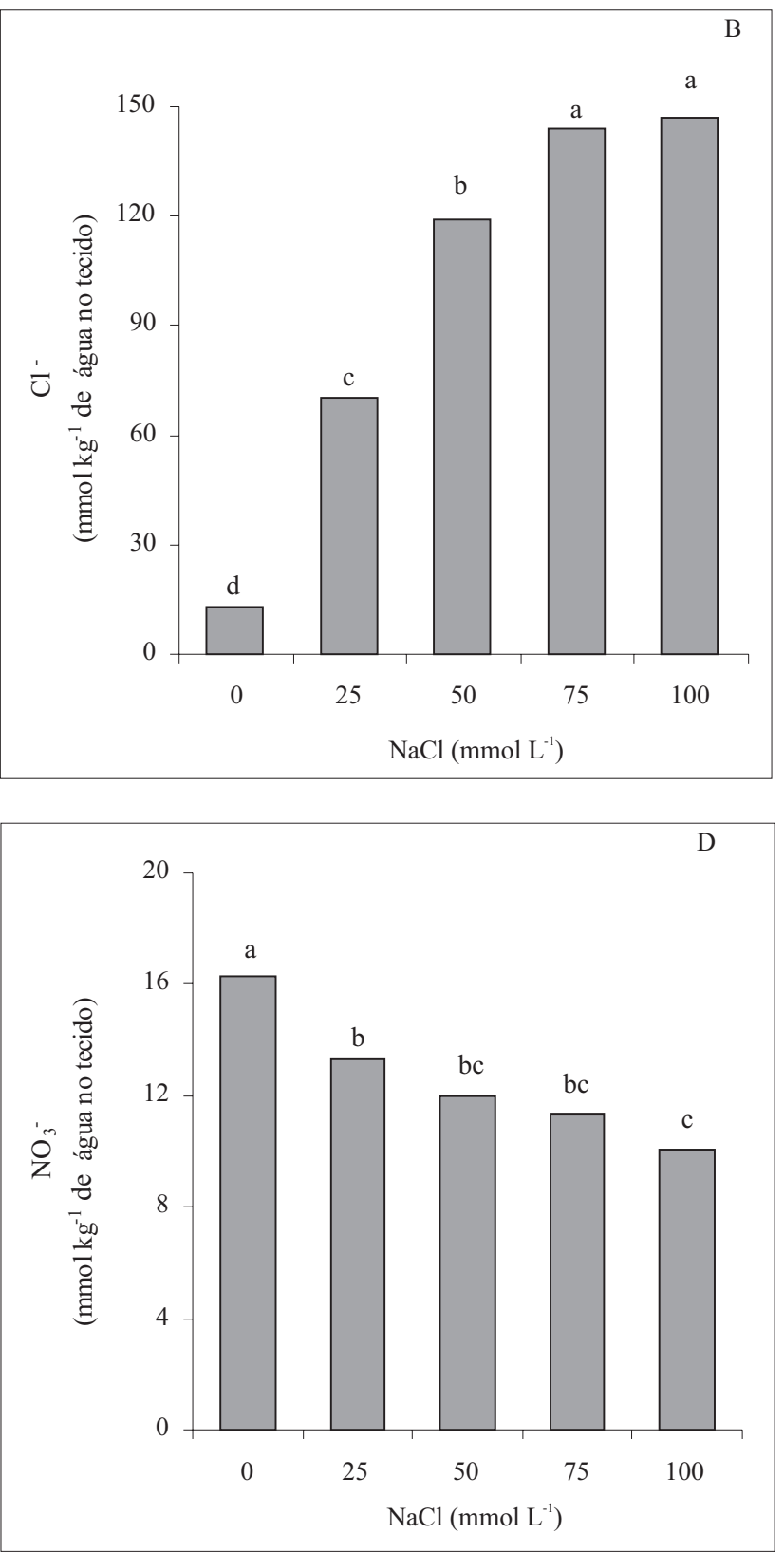

Figura 2. Conteúdos de sódio (A), cloreto (B), potássio (C) e nitrato (D) em folhas de pinhão-manso, expostas a diferentes concentrações de $\mathrm{NaCl}$ durante 15 dias. Tratamentos com letras iguais não diferem entre si a 5\% de probabilidade, pelo teste de Tukey. 
$\mathrm{NO}_{3}{ }^{-}$e $\mathrm{K}^{+}$devem estar relacionadas ao antagonismo por $\mathrm{Cl}^{-}$e $\mathrm{Na}^{+}$, durante a absorção (White \& Broadley, 2001).

A redução intensa nos conteúdos de $\mathrm{K}^{+}$, causada pela salinidade do $\mathrm{NaCl}$, deverá ter sérias implicações no ajustamento osmótico do citosol e organelas de folhas de pinhão-manso. De fato, nas plantas controle, esse soluto mostrou contribuição de aproximadamente 50\% no ajustamento osmótico, enquanto nas plantas tratadas com $100 \mathrm{mmol} \mathrm{L}^{-1}$ de $\mathrm{NaCl}$, essa contribuição foi de apenas 5\% (Tabela 1). Esse tipo de efeito é observado em outras glicófitas (Lacerda et al., 2003), mas não com essa intensidade observada em pinhão-manso. $\mathrm{Na}$ maioria das espécies, a redução no conteúdo de $\mathrm{K}^{+}$ causado pelo $\mathrm{NaCl}$ é muito mais intensa nas raízes do que nas folhas (Ferreira-Silva et al., 2008), enquanto nas halófitas do gênero Atriplex esse efeito ocorre nos dois órgãos (Silveira et al., 2009). Adicionalmente, a contribuição do nitrato, para o potencial osmótico foliar de plantas de pinhão-manso, também foi reduzida pela salinidade que variou de 4 a 1,5\% (Tabela 1).

Os conteúdos de aminoácidos livres totais em plantas com estresse, em comparação às de plantascontrole, permaneceram praticamente inalterados até a concentração de $50 \mathrm{mmol} \mathrm{L}^{-1} \mathrm{de} \mathrm{NaCl}$; todavia, nos níveis de $75 \mathrm{e} 100 \mathrm{mmolL}^{-1}$, houve aumento significativo de 28 e $52 \%$, respectivamente (Figura 3 A), causado provavelmente pela degradação ou redução na síntese protéica, já que ocorreu queda nos níveis de proteínas totais. Dados semelhantes foram obtidos por Lacerda et al. (2003), em plantas de sorgo forrageiro, e por Silveira et al. (2003), em plantas de cajueiro expostas a $100 \mathrm{mmol} \mathrm{L}^{-1}$ de $\mathrm{NaCl}$.

Nas plantas-controle de pinhão-manso, os aminoácidos livres totais mostraram contribuição relativa de aproximadamente $8 \%$ para o ajustamento osmótico, enquanto nas plantas com estresse a contribuição média caiu para cerca de 6\% (Tabela 2). Se os aminoácidos livres estão localizados principalmente no citosol

Tabela 1. Contribuição relativa (\%) de solutos inorgânicos, na osmolalidade total das folhas de plantas de pinhãomanso, expostas a diferentes concentrações de $\mathrm{NaCl}$ durante 15 dias.

\begin{tabular}{ccrrr}
\hline $\mathrm{NaCl}\left(\mathrm{mmol} \mathrm{L}^{-1}\right)$ & $\mathrm{Na}^{+}$ & \multicolumn{1}{c}{$\mathrm{K}^{+}$} & $\mathrm{Cl}^{-}$ & $\mathrm{NO}_{3}^{-}$ \\
\hline 0 & 17,40 & 50,54 & 3,79 & 4,24 \\
25 & 48,57 & 17,01 & 14,15 & 2,70 \\
50 & 54,73 & 7,92 & 18,78 & 1,90 \\
75 & 53,64 & 5,46 & 23,38 & 1,60 \\
100 & 50,80 & 5,30 & 23,22 & 1,49 \\
\hline
\end{tabular}

e organelas e a concentração nessa fração celular pode ser até dez vezes maior em comparação àquela determinada na fração celular total (Silveira et al., 2009), pode-se inferir que os aminoácidos mostram grande importância no ajustamento osmótico de folhas de pinhão-manso, submetido ou não ao estresse salino.

O conteúdo de prolina aumentou gradativamente até a concentração de $75 \mathrm{mmol} \mathrm{L}^{-1}$ de $\mathrm{NaCl}$ e, no nível mais elevado de sal houve aumento de $94 \%$ em relação ao controle. A despeito desse aumento nas plantas com estresse, a contribuição desse soluto compatível para o potencial osmótico, em folhas de pinhão-manso, foi desprezível com valor máximo de 0,04\% (Tabela 2). Existe muita controvérsia sobre o papel osmótico efetivo da prolina, nas plantas submetidas ao estresse salino, isto é, se sua acumulação seria simplesmente uma decorrência de distúrbios metabólicos, no metabolismo de aminoácidos e proteínas (Silveira et al., 2003), ou de caráter genético adaptativo. No presente estudo, em razão das concentrações muito baixas atingidas por esse aminoácido, é mais provável que o aumento na acumulação tenha sido induzido mais pelos danos causadas pelo $\mathrm{NaCl}$ (Silveira et al., 2009).

Tem-se atribuído participação dos solutos orgânicos acumulados em tecidos de plantas expostas a salinidade no ajustamento osmótico e na proteção de estruturas celulares (Strange, 2004). Diversos estudos têm demonstrado que a acumulação de solutos compatíveis, como prolina e glicina betaína, está relacionada à resistência a estresses abióticos, o que indica que esses solutos têm papel na osmoproteção (Asharaf \& Harris, 2004). No entanto, outros estudos têm indicado que a acumulação de solutos orgânicos, em condições ambientais adversas, deve estar mais relacionada a distúrbios metabólicos do que ao ajustamento osmótico (Lutts et al., 1999).

O conteúdo de glicina betaína não mostrou mudanças significativas na comparação entre plantas-controle e com estresse (Figura 3 D). Esse soluto contribuiu com aproximadamente $6 \%$, no ajustamento osmótico das plantas não tratadas, e em média com $4 \%$ nas plantas tratadas com $\mathrm{NaCl}$ (Tabela 2). Como a glicina betaína está situada principalmente no citosol e cloroplastos, que ocupam volume de 5 a $10 \%$ do volume celular, sua concentração pode estar subestimada em relação às frações encontradas para esse soluto, e pode ser até dez vezes maior do que os valores indicados na 
Figura 3 D. (Silveira et al., 2009). Assim, na dose mais elevada de $\mathrm{NaCl}$, a glicina betaína pode atingir concentração de $28 \mathrm{mmol} \mathrm{L}^{-1}$ na base de água de tecido o que corresponde a aproximadamente $280 \mathrm{mmol} \mathrm{kg}{ }^{-1}$. Essa concentração é suficiente para que esse soluto exerça efeitos osmóticos e protetores nas células de folhas de pinhão-manso, como já observado em outras espécies acumuladoras de glicina betaína. É provável
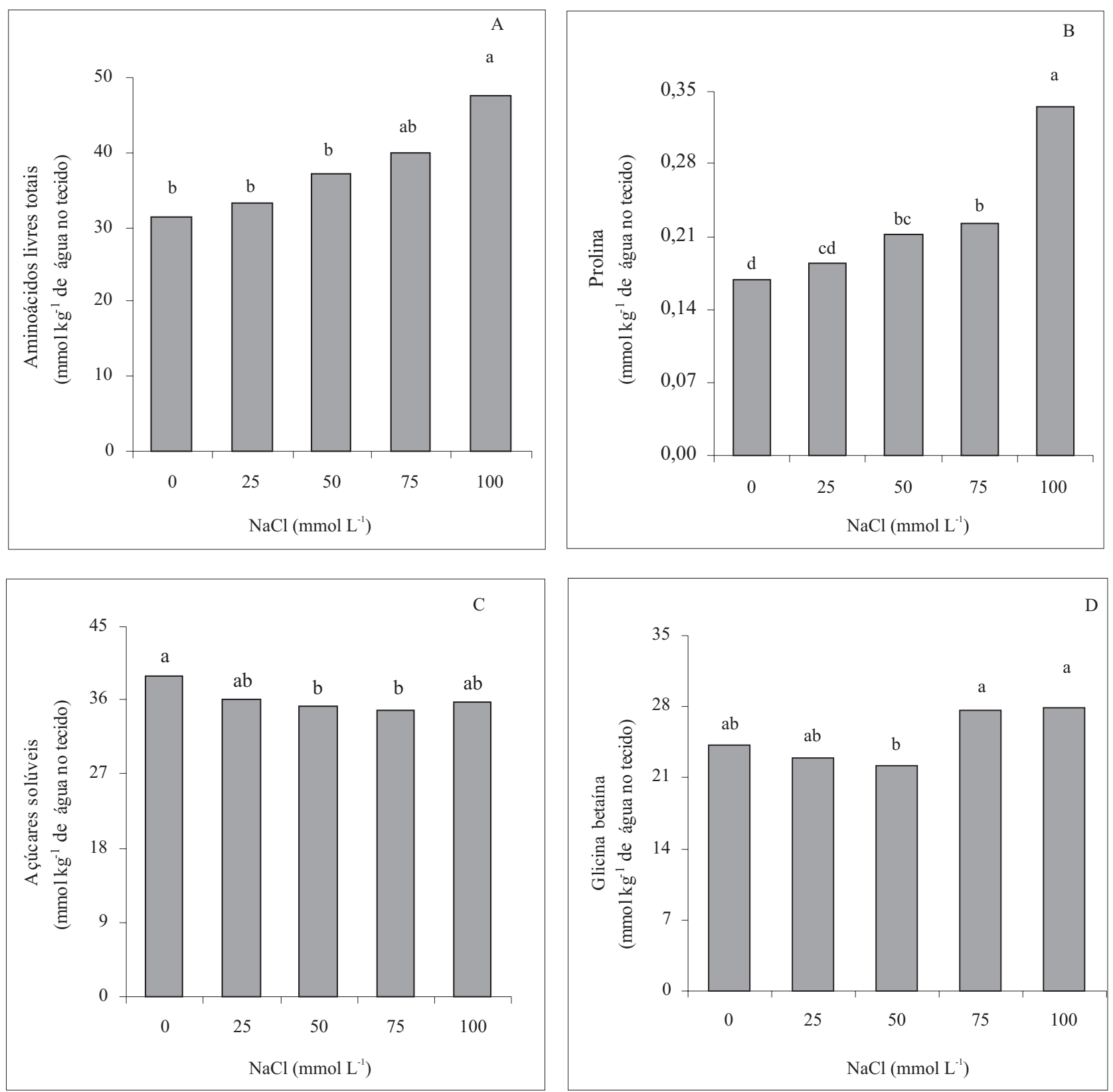

Figura 3. Conteúdos de aminoácidos livres totais (A), prolina (B), açúcares solúveis (C) e glicina betaína (D) em folhas de pinhão-manso, expostas a diferentes concentrações de $\mathrm{NaCl}$ durante 15 dias. Tratamentos com letras iguais não diferem entre si a $5 \%$ de probabilidade, pelo teste de Tukey. 
salino (Figura $3 \mathrm{C}$ ). Esses solutos contribuíram com aproximadamente $10 \%$ do ajustamento osmótico das plantas não tratadas e, em média, com 5,5\% nas plantas tratadas com $\mathrm{NaCl}$ (Tabela 2). Resultados semelhantes foram encontrados em clones de cajueiro por Ferreira-Silva et al. (2008), que concluíram que o papel desse soluto orgânico na osmorregulação foi pouco expressivo.

Diferentemente, Lacerda et al. (2003) observaram acréscimos nos teores de açúcar em plantas de sorgo forrageiro submetidas ao estresse salino, o que determinou um papel mais efetivo para o ajustamento osmótico e crescimento dessas plantas. Segundo Sánches et al. (1998), não é possível saber a real contribuição de açúcares no ajustamento osmótico durante o estresse salino, sem o conhecimento da proporção entre monossacarídeos, dissacarídeos e oligossacarídeos. A redução no conteúdo de açúcares solúveis, assim como na sua contribuição relativa no potencial osmótico em folhas de pinhão-manso, em condições de salinidade, deve estar relacionada à queda na fotossíntese ou mesmo à maior taxa de migração via floema para outras partes da planta (Taiz \& Zeigher, 2004).

No tocante à contribuição relativa dos solutos inorgânicos e orgânicos para o ajustamento osmótico, a maior contribuição relativa de $\mathrm{Na}^{+} \mathrm{e} \mathrm{Cl}^{-}$em folhas de plantas estressadas são indicadores que o pinhãomanso possui algumas características semelhantes a de espécies halófitas que exibem grande avidez por íons salinos (Silveira et al., 2009). A contribuição excessiva dos íons salinos é indicação de que o pinhão-manso se ajusta osmoticamente a concentrações elevadas de $\mathrm{NaCl}$, basicamente pelo uso do sódio e do cloreto, principalmente o $\mathrm{Na}^{+}$. Esses resultados corroboram os de Alarcón et al. (1993), que observaram em algumas espécies de tomate não domesticadas, expostas à

Tabela 2. Contribuição relativa (\%) de solutos orgânicos, na osmolalidade total das folhas de plantas de pinhão-manso, expostas a diferentes concentrações de $\mathrm{NaCl}$ durante 15 dias.

\begin{tabular}{ccccc}
\hline $\mathrm{NaCl}\left(\mathrm{mmol} \mathrm{L}^{-1}\right)$ & AA totais & Prolina & $\begin{array}{c}\text { Açúcares } \\
\text { solúveis }\end{array}$ & Glicina betaína \\
\hline 0 & 7,92 & 0,05 & 10,07 & 5,88 \\
25 & 6,59 & 0,04 & 6,45 & 4,07 \\
50 & 6,05 & 0,03 & 5,73 & 3,70 \\
75 & 5,69 & 0,03 & 4,93 & 3,93 \\
100 & 5,58 & 0,04 & 4,60 & 3,67 \\
\hline
\end{tabular}

(1)Aminoácidos livres totais. salinidade por período longo, um ajustamento osmótico quase exclusivamente à custa dos íons sódio e cloreto.

Ao contrário dos íons salinos $\left(\mathrm{Na}^{+} \mathrm{e} \mathrm{Cl}-\right.$ ), o potássio se caracterizou por apresentar baixa contribuição relativa para oajustamento osmótico, em folhas depinhão-manso submetidas à elevadas salinidade. Em concentrações altas de $\mathrm{Na}^{+}$, a absorção de $\mathrm{K}^{+}$é inibida por meio de um transportador com afinidade alta a $\mathrm{K}^{+}-\mathrm{Na}^{+}$, e esse transportador opera como um sistema de absorção para $\mathrm{Na}^{+}$(Taiz \& Zeigher, 2004). Esses resultados corroboram os de Patade et al. (2008), que observaram em cana-de-açúcar uma contribuição pouco efetiva do $\mathrm{K}^{+}$, no ajustamento osmótico em condições de alta salinidade. Embora o potássio desempenhe importante papel no ajustamento osmótico em espécies glicófitas, plantas de pinhão-manso utilizaram intensamente esse íon para se ajustar osmoticamente na ausência ou em baixas concentrações de $\mathrm{NaCl}$.

Dos solutos orgânicos estudados no presente trabalho, somente a fração aminoácidos livres e a prolina tiveram seus conteúdos aumentados nas concentrações mais elevadas de $\mathrm{NaCl}$, em proporção acima daquela observada na massa de matéria seca das folhas. Isso indica que os aminoácidos livres totais, inclusive a prolina, tiveram suas sínteses aumentadas ou suas utilizações metabólicas diminuídas. Entretanto, em termos quantitativos, para o ajustamento osmótico, a participação de prolina mostra menor importância, quando comparada à glicina betaína, apesar de esse último soluto não ter sua acumulação aumentada por efeito do estresse salino.

\section{Conclusões}

1. O pinhão-manso é capaz de se ajustar osmoticamente em presença de salinidade, por redução intensa no potencial osmótico e aumento do estado hídrico das folhas em concentrações elevadas de $\mathrm{NaCl}$.

2. Os íons salinos $\mathrm{Na}^{+}$e $\mathrm{Cl}^{-}$contribuem para a maioria do ajustamento osmótico, e a contribuição do $\mathrm{K}^{+}$é diminuída intensamente pelo $\mathrm{NaCl}$.

3.Aminoácidos livres e açúcares solúveis contribuem semelhantemente para o ajustamento osmótico das plantas com estresse.

4. A glicina betaína é mais importante quantitativamente do que a prolina para o ajustamento osmótico de folhas de pinhão-manso, tanto na ausência quanto na presença de salinidade. 


\section{Agradecimentos}

À Coordenação de Aperfeiçoamento de Pessoal de Nível Superior, Conselho Nacional de Desenvolvimento Científico e Tecnológico, e Fundação Cearense de Apoio ao Desenvolvimento Científico e Tecnológico, pelo auxílio financeiro e bolsas concedidas; ao Instituto Fazenda Tamanduá, São João do Bonfim PB, pela concessão de sementes selecionadas de pinhãomanso.

\section{Referências}

ALARCÓN, J.J.; SANCHEZ-BLANCO, M.J.; BOLARÍN, M.C.; TORRECILLAS, A. Water relations and osmotic adjustment in Lycopersicon esculentum and L. pennellii during short-term salt exposure and recovery. Physiologia Plantarum, v.89, p.441-447, 1993.

ASHRAF, M.; HARRIS, P.J.C. Potential biochemical indicators of salinity tolerance in plants. Plant Science, v.166, p.3-16, 2004.

AZEVEDO NETO, A.D. de; PRISCO, J.T.; ENÉAS FILHO, J.; LACERDA, C.F. de; SILVA, J.V.; COSTA, P.H.A. da; GOMES FILHO, E. Effects of salt stress on plant growth, stomatal response and solute accumulation of different maize genotypes. Revista Brasileira de Fisiologia Vegetal, v.16, p.31-38, 2004.

CATALDO, D.A.; HAROON, M.; SCHRADER, L.E.; YOUNGS, V.L. Rapid colorimetric determination of nitrate in plant tissue by nitration of salicylic acid. Communications in Soil Science and Plant Analysis, v.6, p.71-80, 1975.

DUBOIS, M.; GILLES, K.A.; HAMILTON, J.K.; REBERS, P.A.; SMITH, F. Colorimetric method for determination of sugars and related substances. Analytical Chemistry, v.28, p.350-356, 1956.

FERREIRA-SILVA， S.L.; SILVEIRA，J.A.G.; VOIGT， E.L.; SOARES, L.S.P.; VIÉGAS, R.A. Changes in physiological indicators associated with salt tolerance in two contrasting cashew rootstocks. Revista Brasileira de Fisiologia Vegetal, v.20, p.51-59, 2008.

GARCÍA-SÁNCHEZ， F.; JIFON， J.L.; CARVAJAL， M.; SYVERTSEN, J.P. Gas exchange, chlorophyll and nutrient contents in relation to $\mathrm{Na}^{+}$and $\mathrm{Cl}^{-}$accumulation in 'Sunburst' mandarin grafted on different rootstocks. Plant Science, v.162, p.705-712, 2002.

HOAGLAND, D.R.; ARNON, D.I. The water culture method for growing plants without soil. Berkeley: University of California, 1950. (Circular, 347).

LACERDA, C.F. de; CAMBRAIA, J.; OLIVA, M.A.; RUIZ, H.A.; PRISCO, J.P. Solute accumulation and distribution during shoot and leaf development in two sorghum genotypes under salt stress. Environmental and Experimental Botany, v.49, p.107-120, 2003.
LUTTS, S.; MAJERUS, V.; KINET, J.M. $\mathrm{NaCl}$ effects on proline metabolism in rice (Oryza sativa) seedlings. Physiologia Plantarum, v.105, p.450-458, 1999.

MARTÍNEZ, J.P.; LUTTS, S.; SCHANCK, A.; BAJJI, M.; KINET, J.M. Is osmotic adjustment required for water stress resistance in the Mediterranean shrub Atriplex halimus L.? Journal of Plant Physiology, v.161, p.1041-1051, 2004.

MELONI, D.A.; GULOTTA, M.R.; MARTÍNEZ, C.A.; OLIVA, M.A. The effects of salt stress on growth, nitrate reduction and proline and glycine betaine accumulation in Prosopis alba. Revista Brasileira de Fisiologia Vegetal, v.16, p.39-46, 2004.

OTTOW, E.A.; BRINKER, M.; TEICHMANN, T.; FRITZ, E.; KAISER, W.; BROSCHÉ, M.; KANGASJÄRVI, J.; JIANG, X.; POLLE, A. Populus euphratica displays apoplastic sodium accumulation, osmotic adjustment by decreases in calcium and soluble carbohydrates, and develops leaf succulence under salt stress. Plant Physiology, v.139, p.1762-1772, 2005.

PATADE, V.Y.; SUPRASANNA, P.; BAPAT, V.A. Effects of salt stress in relation to osmotic adjustment on sugarcane (Saccharum officinarum L.) callus cultures. Plant Growth Regulation, v.55, p.169-173, 2008.

SAKAMOTO, A.; MURATA, N. The role of glycine betaine in the protection of plants from stress: clues from transgenic plants. Plant Cell Environment, v.25, p.163-171, 2002.

SÁNCHEZ, F.J.; MANZANARES, M.; ANDRES, E.F. de; TENÓRIO, J.L.; AYERBE, L. Turgor maintenance, osmotic adjustment and soluble sugar and proline accumulation in 49 pea cultivars in response to water stress. Field Crops Research, v.59, p.225-235, 1998.

SATURNINO, H.M.; PACHECO, D.D.; KAKIDA, J.; TOMINAGA, N.; GONÇALVES, N.P. Cultura do pinhão-manso (Jatropha curcas L.). Informe Agropecuário, v.26, p.44-78, 2005.

SILVEIRA, J.A.G.; ARAÚJO, S.A.M.; LIMA, J.P.M.S.; VIÉGAS, R.A. Roots and leaves display contrasting osmotic adjustment mechanisms in response to $\mathrm{NaCl}$-salinity in Atriplex nummularia. Environmental and Experimental Botany, v.66, p.1-8, 2009.

SILVEIRA, J.A.G.; VIÉGAS, R.D.; ROCHA, I.M.A. da; MOREIRA, A.C.D.M.; MOREIRA, R.D.; OLIVEIRA, J.T.A. Proline accumulation and glutamine synthetase activity are increased by salt-induced proteolysis in cashew leaves. Journal of Plant Physiology, v.160, p.115-123, 2003.

STRANGE, K. Cellular volume homeostasis. Advances in physiology education, v.28, p.155-159, 2004.

TAIZ, L.; ZEIGHER, E. Plant physiology. 3.ed. Porto Alegre: ARTMED, 2004. 719p.

WHITE, P.J.; BROADLEY, M.R. Chloride in soils and its uptake and movement within the plant: a review. Annals of Botany, v.88, p.967-988, 2001 .

Recebido em 8 de dezembro de 2008 e aprovado em 30 de abril de 2009 